\title{
Association of C4125A Polymorphisms of $M D R-1$ gene with childhood acute lymphoblastic leukaemia in Egyptian
}

\author{
Roba M. Talaat ${ }^{*}$, Medhat YK. El-Kelliny¹, Basima A. El-Akhras¹, Rania M. Bakry², \\ Khaled F. Riad², Adel A. Guirgis ${ }^{1}$
}
${ }^{1}$ Molecular Biology Department, Genetic Engineering and Biotechnology Research Institute (GEBRI), University of Sadat City, Egypt.

${ }^{2}$ South Egypt Cancer Institute, Assiute University, Egypt.

Corresponding author: E-mail address: roba.talaat@gebri.usc.edu.eg \& robamtalaat@gmail.com

\begin{abstract}
Acute lymphoblastic leukemia (ALL) is the most common malignancy in children, though the etiology of the leukemia is poorly understood, both genetic and environmental factors appear to be involved. To investigate the possible role of MDR-1 (C4125A) polymorphism as risk factor for the development of ALL in this study on Egyptian children and to evaluate its prognostic role. Typing of MDR-1 (C4125A) polymorphism was done using RFLP-PCR for 120 patients with ALL and 100 healthy controls. The C allele (100\%) and CC genotype (100\%) were insignificant in both groups. Also, no relation between clinical data and C4125A genotypes. Thus, MDR-1 (C4125A) SNP may be not risk factor for the development of pediatric ALL in Egyptian patients.
\end{abstract}

Key words: ALL, MDR-1, polymorphism, Egyptian

\section{INTRODUCTION}

Acute lymphoblastic leukemia (ALL) is the most common malignancy diagnosed during childhood (Tai et al., 2017). Acute leukemia, the main subtype of childhood leukemia which is characterized by the uncontrolled proliferation of hematopoietic cells in the bone marrow, is the major pediatric cancer all over the world with an approximately 20\% mortality rate in each year (Pui et al., 2004; Greaves, 2006). Dysregulation of immune responses may be a cause of ALL. Although epidemiological data showed that the transplacental carcinogen exposure such as ionizing radiation as a basis for infant leukemia associated with MLL gene fusion, the role of environmental carcinogenesis as postnatal high-dose radiation, chemotherapeutic agents in ALL is currently undefined. In addition environmental risk factors may have different effects on the risk of childhood leukemia depending on the timing of exposure and individual genetic susceptibility (Sandler and Ross, 1997; Greaves, 2006). Most ALL treatment protocols include an induction phase with three to four drugs glucocorticoids, mitotic inhibitors, an anthracycline, and/or asparaginase) to achieve clinical remission. This is followed by a consolidation phase [mainly methotrexate (MTX) and 6-mercaptopurine (6MP)], intrathecal therapy with MTX, and finally a continuation phase lasting 2-3 years from the time of diagnosis (Muwakkit et al., 2012).

Although cancer therapy for childhood ALL has remarkably improved during the past two decades and normal life expectancy is a reality for many patients, a considerable portion of patients cannot permanently be cured. One major reason is the development of drug resistance. The human multi drug resistance gene (MDR-1), located on chromosome 7q21, comprises 28 exons and encodes a $170 \mathrm{KD}$ integral membrane protein product $\mathrm{P}$ glycoprotein (Pgp), which belongs to the ATP binding cassette (ABC) super family of transporters resides in the plasma membrane and functions as an efflux transporter of a wide variety of natural compounds and lipophilic xenobiotics (Lin et al., 2003). The expression of the multidrug resistance gene, MDR-1, and its gene product P-gp, is now well analyzed in leukemias. Its prognostic relevance for the development of drug resistance and worse outcome of patients has been unambiguously shown for many tumor types including myeloid leukemia (Chauncey, 2001; Efferth, 2001). In ALL the relevance of $\mathrm{MDRl} / \mathrm{P}$-gpis, however, still under debate. While some authors found that high MDRl/P-gpexpression and function is associated with failure of chemotherapy and adverse prognosis 
(Tafuri et al., 2002) others did not (Mottonen et al., 2001).

The most frequent types of genetic variation within the human genome are single nucleotide polymorphisms (SNPs), which are thought to contribute in large part to the phenotypic differences observed within species. Such genetic polymorphisms in genes mediating drug transport and drug metabolism have been suggested to play an important role in the variability in survival after cancer therapy (Ekhart et al., 2009). A recent genome-wide analysis showed an association between 102 SNPs and MRD in childhood ALL, suggesting that host genetic variability plays an important role in dictating treatment response (Yang et al., 2009). Specific inherited polymorphisms were also shown to be correlated with drug toxicity in leukemias(Kishi et al., 2007). Interestingly, a silent C3435T polymorphism in exon 26 resulted in more than twofold lower P-gp expression in duodenum and higher plasma concentration of P-gp substrate digoxin in subjects with TT genotype compared with CC carriers (Hoffmeyer et al., 2007). Although some discrepancies were observed,most other studies have also suggested functional relevance of this polymorphism to mRNA, protein or activity levels in a number of tissues (Sakaeda et al., 2001). Also, linkage disequilibrium exists between C3435T and G2677T/A, and several studies have also shown a connection between G2677T/A and the pharmacokinetics of P-gp substrates(Chowbay et al., 2007; Verstuyft et al., 2003) . Another SNP, C1236T, also seems to be linked to C3435T and G2677T/A, but no effect of this SNP on pharmacokinetics has been described. Hence, the present investigation has been planned to identify the association of MDR1 C4125A polymorphism with the development of ALL and it's progression in Egyptian.

\section{MATERIALS AND METHODS}

\section{Patients and controls}

The present study includes 120 ALL cases (66 males and 54 females) after informed consent versus 100 control samples. Blood samples were collected from freshly diagnosed patients with acute leukemia who were reporting at pediatric ALL were evaluated by the Department of Hematology at South Egypt Cancer Institute and Hospital, Assiut University, Egypt. The age and sex of two groups were matched. Patient's clinical data like WBC count, blast\%, platelet count, $\mathrm{Hb}, \mathrm{LDH}$, complete remission (CR) response to therapy and period of disease free survival(DFS) was noted from the tumor registry files with the help of medical oncologist during follow up. Genomic DNA was isolated by Genomic DNA Purification Kit (QIAGEN, Germany) according to manufacturer's instructions (Plasschaert et al., 2004). The quality and concentration of DNA in all samples was measured by using nanodrop (Thermo Scientific).

\section{Genotyping}

Primer sequences and PCR conditions of SNPs in MDR-l gene (C4125A) are presented in Table (1). All polymerase chain reactions (PCR) were performed in the 2720 thermal cycler (Applied Biosystems).

MDR-1 (C4125A) were genotyped by restriction fragment length-PCR (RFLP-PCR) as previously described (Ren et al., 2012); respectively. A $25 \mu 1$ of PCR reaction mixture contained MyTaqTM Red Master Mix (2x) (Maridian life Science Company, USA), 10 pmol of each primer and $150 \mathrm{ng}$ of DNA template. PCR products for MDR-1 (C4125A) were visualized on $2 \%$ agarose gel electrophoresis and the size of the band was $221 \mathrm{bp}$. Digestion of PCR product was occurred by using RsaI (Fermantas) restriction. Homozygous wild CC didn't restricted 221bp, homozygous mutant AA restricted to $199 \mathrm{bp} / 22 \mathrm{bp}$ and heterozygous restricted to $221 \mathrm{bp} / 199 \mathrm{bp} / 22 \mathrm{bp}$.

\section{Statistical analysis}

Statistical analyses were performed by SPSS statistical package version 11 (SPSS, IBM Corporation, USA). Comparisons between pediatric ALL and controls were made by using independent $\mathrm{T}$-test and results were presented as mean $\pm \mathrm{SD}$. Chisquared tests were performed to examine the differences in the allele frequency and genotype distribution between different groups. Odds ratios [with $95 \%$ confidence interval (CI)] were calculated to measure the relative risks in both control and pediatric ALL patients. All values were two-tailed, and $P$ values $<0.05$ were considered to be statistically significant.

\section{RESULTS \\ Patients and controls}

The characteristics of the 120 ALL patients and 100 control subjects were displayed in Table (2). The mean age of pediatric ALL were 6.40 \pm 3.99 (ranged from 1 to 15 years) while the mean age of normal controls was 5.91 \pm 3.45 (ranged from 1 to 15 years). All clinical parameters of ALL patients (sex, immufinophenotypes, white blood cell number .....etc) were summarized in Table (3).

Table 1. Primers and PCR conditions that used to detect polymorphism of MDR-1 gene in Pediatric ALL patients and controls. 


\begin{tabular}{|r|r|r|r|r|}
\hline MDR & Primers & $\begin{array}{r}\text { Restriction } \\
\text { Enzyme }\end{array}$ & $\begin{array}{r}\text { PCR } \\
\text { product } \\
\text { Length }\end{array}$ & $\begin{array}{r}\text { Length of } \\
\text { expected } \\
\text { Bands (bp) }\end{array}$ \\
\hline Exon 28 & FCCAATTTAAATTCTTACCTGT -3' \\
$(4125$ C/A $)$ & Reverse : 5'- & & $221 \mathrm{bp}$ & AA:199, 22 \\
& RCTGTTAGAACTTTACTTTCAGTTC-3' & & AC:221, 199, 22 \\
& CC:221 & \\
\hline
\end{tabular}

Table 2. Demographic and biochemical characteristics of ALL patients and healthy controls.

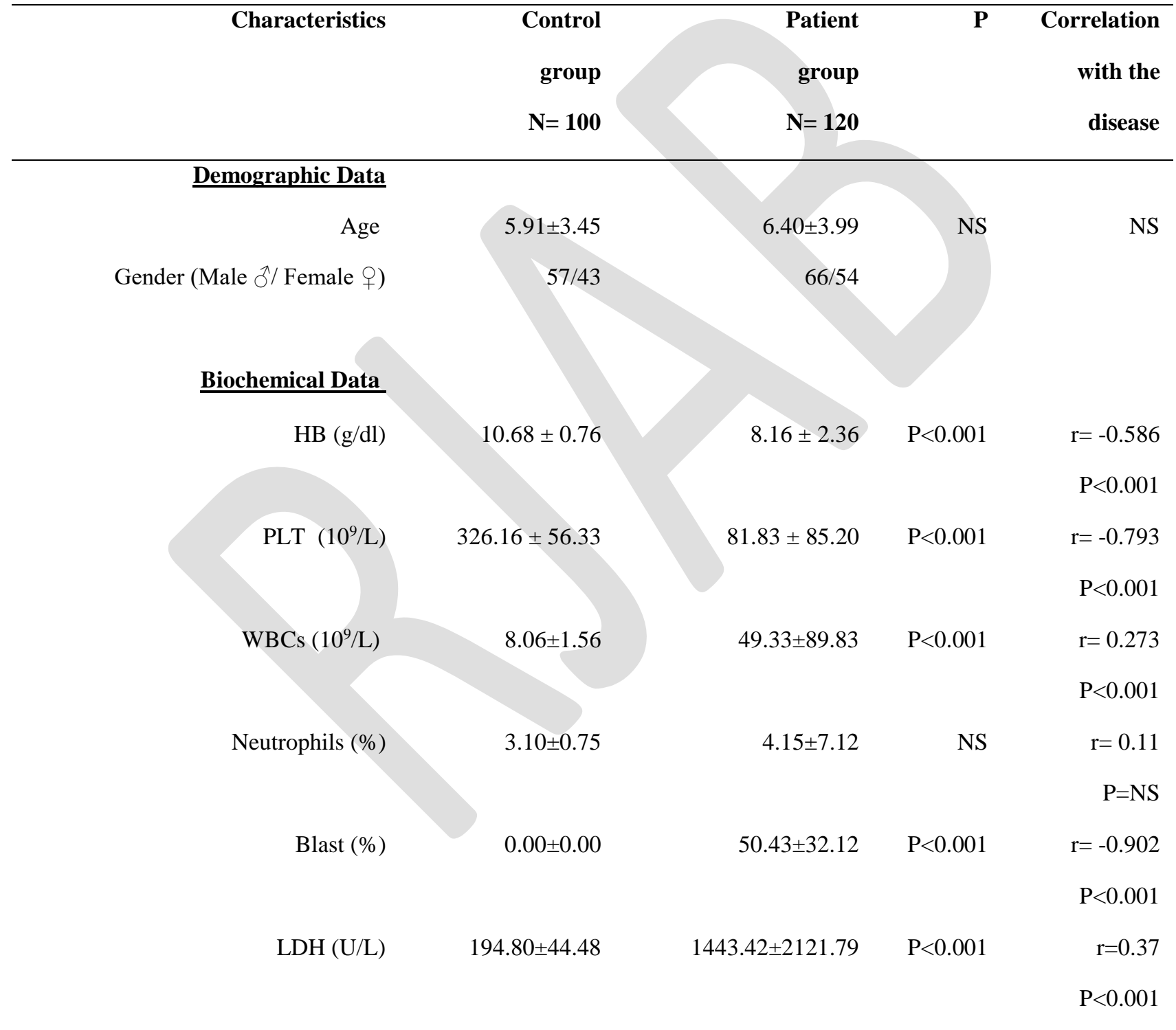

All data are presented as mean \pm SD; HB, haemoglobin; PLT, platelet count; WBCs, white blood cells; LDH, lactate dehydrogenase. 
Table 3. The genotype and allele frequencies of MDR1 gene polymorphisms (and C4125A) in ALL patients and controls.

\begin{tabular}{|c|c|c|c|c|}
\hline Polymorphisms & $\begin{array}{c}\text { Control } \\
(\mathbf{N}=100) \\
\mathbf{N}(\%)\end{array}$ & $\begin{array}{r}\text { Patients } \\
(\mathbf{N}=120) \\
\mathbf{N}(\%)\end{array}$ & $\begin{array}{r}\text { 95\% Confidence Interval } \\
\text { OR (lower-upper) }\end{array}$ & p-value \\
\hline & & & \multicolumn{2}{|c|}{ MDR-1 C4125A (Genotype Frequency } \\
\hline $\mathbf{C C}$ & $100(100)$ & $120(100)$ & -- & -- \\
\hline CA & -- & -- & -- & -- \\
\hline $\mathbf{A A}$ & -- & -- & -- & -- \\
\hline \multicolumn{5}{|c|}{ Allele Frequency } \\
\hline $\mathrm{C}^{-}$ & $200(100)$ & $240(100)$ & $1.199(0.023-60.72)$ & NS \\
\hline A & -- & -- & -- & \\
\hline
\end{tabular}

NS, not significant.

Table 4. Comparison between C4125A genotypes in pediatric ALL patients related to demographic, clinical and laboratory data.

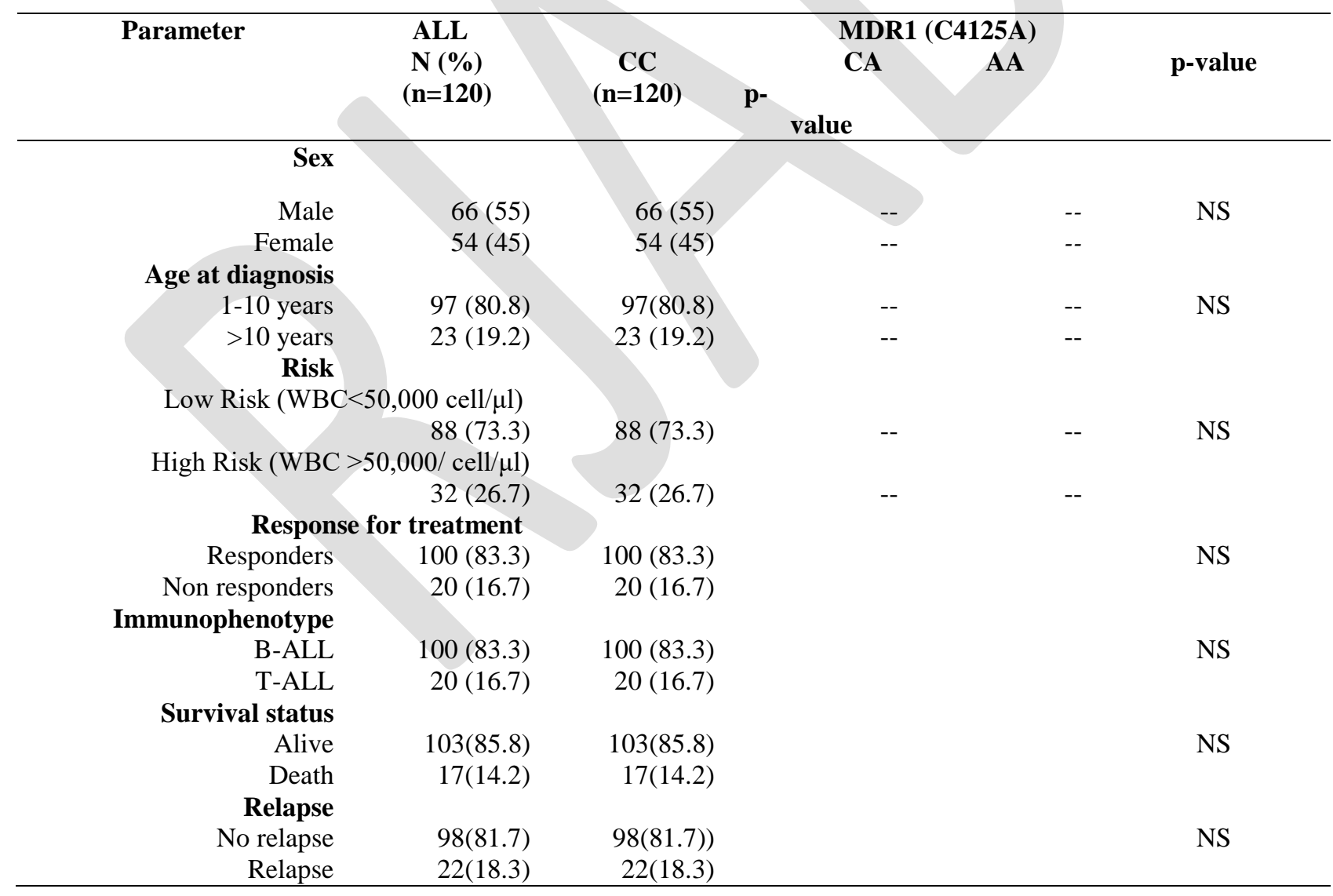

The association between MDR-1 (C4125A) SNP and ALL susceptibility

Table (4) shows the frequency of the analyzed genotypes and alleles for C4125A of MDR$l$ in childhood ALL patients and healthy controls.
C4125A SNP, only one genotype (CC) and one allele of $M D R-1$ (C4125A) were seen. Neither CA/AA genotypes nor A allele were present in ALL patients and normal controls.

\section{Discussion}


To date, most studies investigating the relationship between $M D R 1$ polymorphisms and susceptibility to ALL have focused on different SNPs neglected that SNP C4125A except only study (Ren et al., 2012). Additionally in the Middle East, and to our knowledge, experience is limited despite All data are presented as mean $\pm \mathrm{SD}$; $\mathrm{HB}$, haemoglobin; PLT, platelet count; WBCs, white blood cells; LDH, lactate dehydrogenase

However, CC genotype was the only genotype found in both groups against the other genotypes. These results suggested that MDRI (C4125A) SNP aren't associated with ALL susceptibility in Egyptian population. In opposite to this study, several previous studies confirmed that the relationship between MDRl different SNPs ((C3435T) , (G571A) , (G2677T/A) , (C1236T) ,(T129C) and other polymorphisms) and risk of ALL (Jamroziak et al., 2004; Hattori et al., 2007).

In conclusion, this study showed that MDR-1 (C4125A) may be not contribute to ALL susceptibility in Egyptian population. However, several limitations should be noted. First, the sample size might not be large enough to confirm these results. Second, due to the limited original information, potential gene - gene and gene environment interactions were not evaluated in this study. Third, only one SNP (C4125A) was investigated in the present study. Additional genomic loci (such as C3435T, C1236T) should be covered with studying other SNP.

\section{Reference}

Tai EW, Ward KC, Bonaventure A, Siegel DA, Coleman MP (2017). Survival among children diagnosed with acute lymphoblastic leukemia in the United States, by race and age, 2001 to 2009: Findings from the CONCORD-2 study. Cancer, 24,5178-89.

Greaves M (2006). Infection, immune responses and the aetiology of childhood leukaemia. Nat Rev Cancer, 6, 193-203.

Pui CH, Schrappe M, Ribeiro R, Niemeyer CM (2004). Childhood and adolescent lymphoid and myeloid leukemia. Hematology Am SocHematolEduc Program, 1, 118-45.

Sandler DP, Ross JA (1997). Epidemiology of acute leukemia in children and adults. SeminOncol, 24, 3-16. the high incidence of polymorphisms in possibly relevant genes such as MDR-1( Zgheib et al., 2014). Thus, this study has focused on the role of MDR-1 (C4125A) with ALL in Egyptian. ALL is the most common malignancy

Muwakkit S, Al-Aridi C, Samra A, Saab R, Mahfouz AR, Farra C, et al (2012).Implementation of an intensive risk-stratified treatment protocol for childrenand adolescents with acute lymphoblastic leukemia in Lebanon. Am JHematol,87,678-83.

Lin JH, Yamazaki M (2003). Role of p-glycoprotein in pharmacokinetics: clinical implications. ClinPharmacokinet, 42, 59-98.

Chauncey TR (2001). Drug resistance mechanisms in acute leukemia.CurrOpinOncol,13, 2126.

Efferth T (2001). The human ATP-binding cassette transporter genefamily: from the bench to the bedside. CurrMol Med,1,45-65.

Tafuri A, Gregori C, Petrucci MT, Ricciardi MR, Mancini M, et al(2002). MDRl protein expression is an independent predictor of complete remission in newly diagnosed adult acute lymphoblastic leukemia. Blood, 100, 974-81.

Mottonen M, Salmi TT, Krusius T and SaarinenPihkala U (2001). M.Initial P-glycoprotein expression in childhood acute lymphoblasticleukemia: no evidence of prognostic impact in followup.PediatrHematolOncol,18, 27-36.

Ekhart C, Rodenhuis S, Smits PH, Beijnen JH, HuitemaAD (2009). An overview of the relations between polymorphismsin drug metabolising enzymes and drug transporters andsurvival after cancer drug treatment. Cancer Treat Rev,35, 18-31.

Yang JJ, Cheng C, Yang W, et al (2009). Genomewideinterrogation of germline genetic variation associatedwith treatment response in childhood acute lymphoblastic leukemia. JAMA,301, 393-403.

Kishi S, Cheng C, French D, et al (2007). Ancestry and phar -macogenetics of antileukemic drug toxicity. Blood, 109, 4151-7. 
Hoffmeyer S, Burk O, von Richter O et al (2000). Functionalpolymorphisms of the human multidrug resistance gene:multiple sequence variations and correlation of one allelewith P-glycoprotein expression and activity in vivo. ProcNatl AcadSci USA ,97,3473-78.

Sakaeda T, Nakamura T, Horinouchi M et al (2001). MDR1genotype-related pharmacokinetics of digoxin after singleoral administration in healthy Japanese subjects. PharmacolRes, 18,1400-04.

Chowbay B, Cumaraswamy S, Cheung YB, Zhou Q, LeeEJ(2003). Genetic polymorphisms in MDR1 and CYP3A4genes in Asians and the influence of MDR1 haplotypeson cyclosporin disposition in heart transplant recipients.Pharmacogenetics ,13,89-95.

Verstuyft C, Schwab M, Schaeffeler E, Kerb R, BrinkmannU, Jaillon P, et al (2003). Digoxin pharmacokinetics andMDR1 genetic polymorphisms. Eur J ClinPharmacol ,58,809-12.

Ren YQ, Han JQ, Cao JB, Li SX, Fan GR (2012). Association of MDR-1 gene polymorphisms with susceptibility to hepatocellular carcinoma in the Chinese population. Asian Pac J Cancer Prev, 13, 5451-4.

Zgheib NK, Akra-Ismail M, Aridi C, et al (2014).Genetic polymorphisms in candidat e genes predict increased toxicity with met hotrexate therapyin Lebanese children wit $\mathrm{h}$ acute lymphoblastic leukemia.

Pharmacogenet Genomics,24,387-96.

Hattori H, Suminoe A, Wada M, et al (2007).Regulatory polymorphisms of multidrug resistance $1(M D R-1)$ gene are associated with the development of childhood acute lymphoblastic leukemia. Leuk Res, 31,1633-40.

Jamroziak K, Młynarski W, Balcerczak E, et al (2004). Functional C3435T polymorphism of $M D R-1$ gene: an impact on genetic susceptibility and clinical outcome of childhood acute lymphoblastic leukemia. Eur J Haematol, 72, 314-21.

Plasschaert SL, Groninger E, Boezen $\mathrm{M}$, et al (2004). Influence of functional polymorphisms of the $M D R-1$ gene on vincristine pharmacokinetics in childhood acute lymphoblastic leukemia. ClinPharmacolTher, 76, 220-9. 